\title{
A spectrofluorometric investigation, using 1-anilino- naphthalene-8-sulphonate, of the interaction between washed bovine spermatozoa and seminal plasma or egg-yolk lipoprotein
}

\author{
B. J. MacDonald and J. A. Foulkes \\ Cattle Breeding Centre, Shinfield, Reading RG2 9BZ, U.K.
}

\begin{abstract}
Summary. The dye 1-anilino-naphthalene-8-sulphonate (ANS) bound at $94.5 \pm 2.7$ pmol per $10^{6}$ spermatozoa $\left(K_{\mathrm{D}}=1.83 \pm 0.13 \times 10^{-5} \mathrm{M}\right)$ and $7.30 \pm 0.17$ pmol per mg seminal plasma protein $\left(K_{\mathrm{D}}=2.19 \pm 0.06 \times 10^{-5} \mathrm{M}\right)$. Equilibration of excess ANS with a mixture of washed spermatozoa and seminal plasma resulted in a significant increase in fluorescence over that calculated by summation of the individual levels $(P<0.05)$. A less pronounced but significant increase was seen when an egg-yolk lipoprotein, previously shown to have cryoprotective properties, was similarly added to washed spermatozoa $(P<0.05)$. This increase in fluorescence was not reduced by washing spermatozoa-lipoprotein mixtures, suggesting that an interaction between the lipoprotein and the cell membrane had occurred.
\end{abstract}

\section{Introduction}

Egg yolk is widely regarded as an essential ingredient of diluents employed for the freezing of bovine spermatozoa. Such biological supplements are not ideal since they are variable in composition and are potential carriers of pathogens. Attempts have been made to characterize the components in egg yolk that provide protection against damage during cooling, freezing and thawing. Phospholipids (Kampschmidt, Mayer \& Herman, 1953), phosphatidyl choline (Martin, 1963; Lanz, Pickett \& Komarek, 1965; Masuda \& Nishikawa, 1972), various lipid extracts and lipoprotein fractions (Bialy, Ludwick, Hess \& Ely, 1957; Gebauer, Pickett, Komarek \& Gaurya, 1970) and specific lipoproteins (Masuda \& Nishikawa, 1972; Foulkes, 1977) have all been reported to provide cryoprotection to spermatozoa.

The interaction of fluorescent dyes with membrane components has proved a useful tool for investigation of the physico-chemical properties of membranes (Datta \& Penefsky, 1970; Aithal, Kalra \& Brodie, 1974; Peterson, Bundman \& Freund, 1978). The dye 1-anilino-naphthalene-8-sulphonate (ANS) fluoresces strongly when adsorbed to proteins in solution (Weber \& Laurence, 1954) and when bound to human spermatozoa (Mercado \& Rosado, 1973). Microscopical studies have indicated that the fluorescence resulting from ANS interaction with ram spermatozoa is reduced by prior incubation of spermatozoa with egg yolk (Watson, 1975). Watson (1979) concluded that washing spermatozoa to remove egg yolk before the addition of ANS did not prevent this fluorescence inhibition. This supported the contention (Foulkes, 1977) that egg-yolk constituents bind firmly to sperm membranes.

In the present study fluorescence resulting from ANS interaction with spermatozoa and seminal plasma proteins was used to investigate dye binding sites on the sperm membrane. The 
interaction of bovine spermatozoa with a particular egg-yolk lipoprotein, previously shown to confer cryoprotection (Foulkes \& Stewart, 1977), was investigated by using ANS fluorescence.

\section{Materials and General Methods}

\section{Preparation of spermatozoa}

Ejaculates were collected from fertile bulls by artificial vagina and were combined at $30^{\circ} \mathrm{C}$. The concentration of spermatozoa was determined using a calibrated EEL colorimeter (Cox \& Melrose, 1953) and motility was assessed by examination under a microscope at $40^{\circ} \mathrm{C}$. After dilution in 0.1 M-phosphate-buffered saline (PBS, $\mathrm{pH} \mathrm{6.9)} \mathrm{the} \mathrm{spermatozoa} \mathrm{were} \mathrm{washed} \mathrm{by}$ centrifugation through $7.5 \%$ (w/v) Ficoll 400 (Pharmacia, Uppsala, Sweden) in PBS to remove seminal plasma components (Harrison, 1976). Aliquots of seminal plasma (the supernatant) were collected and stored at $4^{\circ} \mathrm{C}$. Washed spermatozoa were resuspended in PBS at $30^{\circ} \mathrm{C}$ with mild agitation over a period of $60 \mathrm{~min}$.

\section{Preparation of egg-yolk lipoprotein}

Egg-yolk lipoprotein (Fraction III) was prepared using density flotation and gel filtration techniques (Foulkes, 1977). The eluate volume was reduced with an Amicon $\mathrm{CH} 4$ concentrator and the protein concentration was determined (Lowry, Rosebrough, Farr \& Randall, 1951).

\section{Fluorometry}

Fluorescence measurements were made with a recording spectrofluorometer (Perkin-Elmer MPF-2A) at $475 \mathrm{~nm}$ using the procedures described by Mercado \& Rosado (1973) or with an EEL 244 fluorometer with excitation at $366 \mathrm{~nm}$ using the $0 \times 1$ filter and emission recorded at $475 \mathrm{~nm}$. Both instruments were calibrated with quinine sulphate standards. After addition of ANS (Sigma Chemical Company, Poole, Dorset), the reaction mixtures were incubated at $30^{\circ} \mathrm{C}$ for $5 \mathrm{~min}$ to ensure equilibration before fluorescence measurement. Fluorescence emission spectra following excitation at $366 \mathrm{~nm}$ were recorded after the addition of ANS to egg-yolk lipoprotein, washed spermatozoa and lipoprotein-sperm mixtures.

\section{Detailed Methods and Results}

\section{Determination of binding characteristics}

Aliquots $(4 \mathrm{ml})$ containing washed spermatozoa $\left(1-10 \times 10^{6}\right.$ cells $)$ or seminal plasma (20-120 $\mu \mathrm{g}$ protein) were titrated (Text-fig. 1) with ANS to a maximum concentration of 100 $\mu$ M-ANS (Datta \& Penefsky, 1970). The sample volume was chosen to limit any increase in volume to less than 5\% (Mercado \& Rosado, 1973), thereby minimizing its effect on the level of fluorescence.

As a preliminary to calculation of the proportion of dye bound at increasing ANS concentrations, co-ordinates along the line 'maximum fluorescence on ANS concentration' were determined as follows. ANS (100-400 nM) was titrated with washed spermatozoa (Text-fig. 2a) or seminal plasma (Text-fig. 2b). The reciprocal of fluorescence was plotted against the reciprocal of number of spermatozoa/ml (Text-fig. 3a) or protein concentration (Text-fig. $3 \mathrm{~b}$ ) and each line was extrapolated to the ordinate by regression analysis. The maximum fluorescence at each ANS concentration was calculated as the reciprocal of the ordinate intercept (Brocklehurst, Freedman, Hancock \& Radda, 1970). These values were plotted against ANS concentration and the theoretical maximum fluorescence line was calculated by regression analysis. Fluorescence 


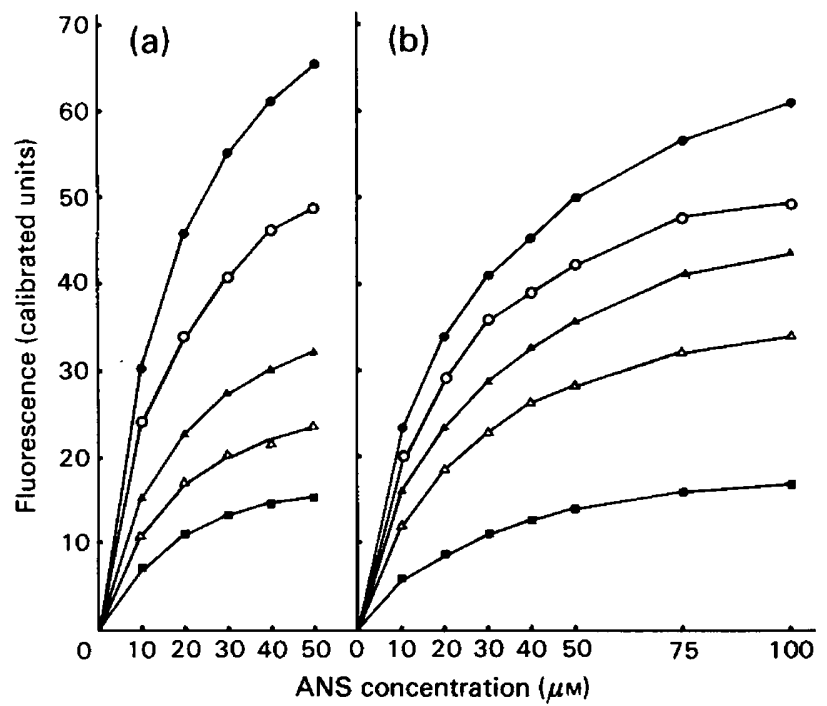

Text-fig. 1. Fluorescence after addition of increasing concentrations of ANS to (a) spermatozoa and (b) seminal plasma protein.

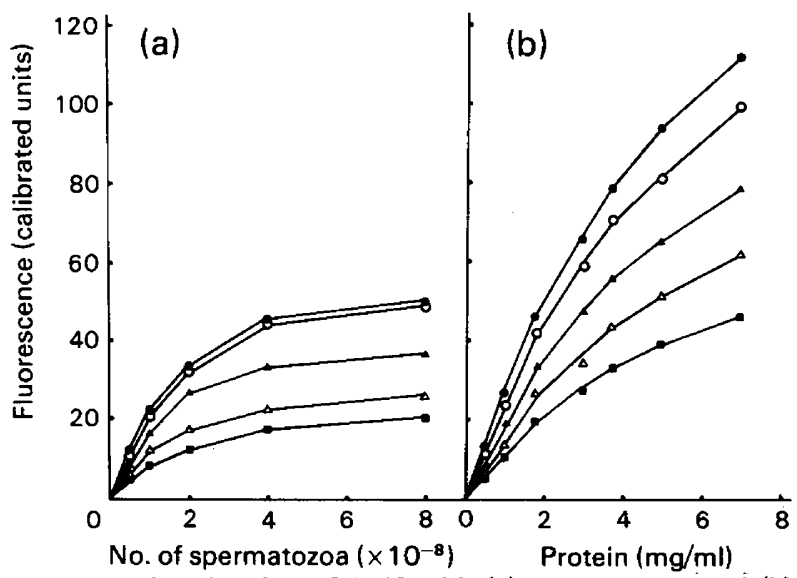

Text-fig. 2. Fluorescence after titration of ANS with (a) spermatozoa and (b) seminal plasma.

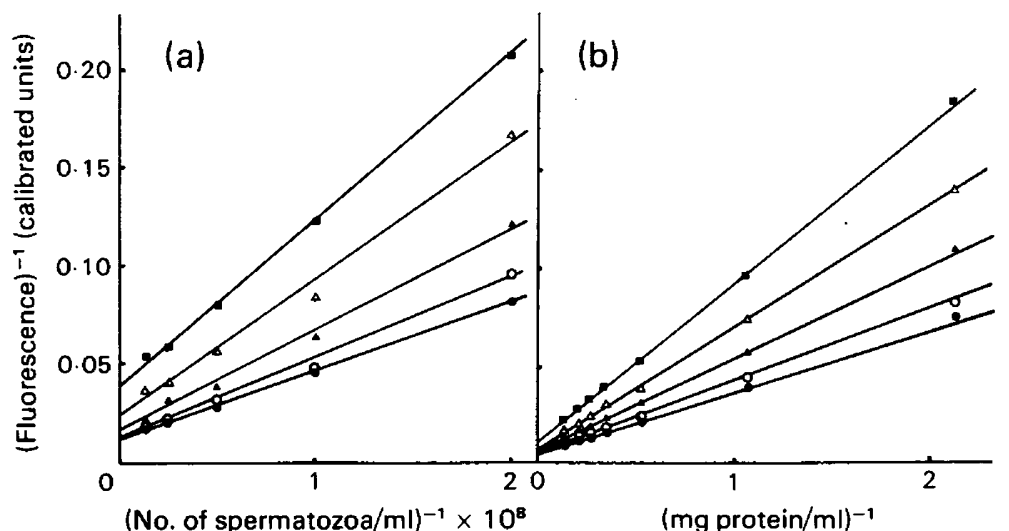

Text-fig. 3. Double reciprocal plot of fluorescence against (a) number of spermatozoa $/ \mathrm{ml}$ and (b) concentration of seminal plasma protein after addition to ANS. 
values observed following binding of higher concentrations of ANS to spermatozoa or seminal plasma components (Text-fig. 1) were subtracted from the corresponding theoretical maximum fluorescence and the proportion of unbound dye was determined.

The statistical dissociation constant $\left(K_{\mathrm{D}}\right)$ and number of dye binding sites $(n)$ were evaluated by two methods. The ratios of bound ANS:free ANS were plotted against the amount of ANS bound (Scatchard, 1949; Datta \& Penefsky, 1970; Mercado \& Rosado, 1973; Aithal et al., 1974) for each sperm or seminal plasma protein concentration (Text-fig. 4). $K_{\mathrm{D}}$ was determined as the negative of the value calculated for the gradient and $n$ as the ordinate intercept (Table 1). Alternatively, the reciprocal of the concentration of ANS bound was plotted against the reciprocal of the concentration of unbound dye (Klotz, Walker \& Pivan, 1946; Laurence, 1952; Weber \& Young, 1964a, b; Mercado \& Rosado, 1973). The value for $n$ was determined as the reciprocal of the ordinate intercept and $K_{\mathrm{D}}$ as the product of the gradient and $n$ (Text-fig. 5; Table 1). The bovine sperm membrane had approximately $6 \times 10^{7}$ dye binding sites per cell after calculation from the data in Table 1 using the Avogadro constant.
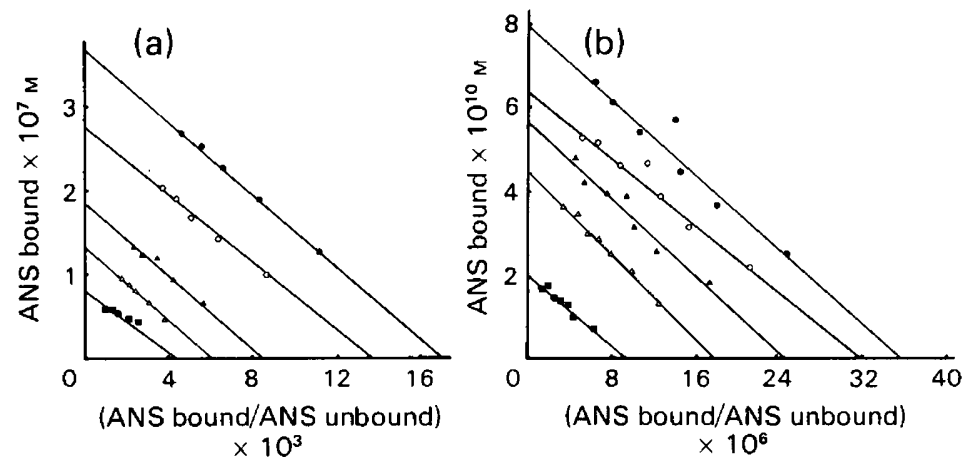

Text-fig. 4. Concentration of bound ANS plotted against the ratio of bound to unbound ANS for (a) spermatozoa and (b) seminal plasma protein.
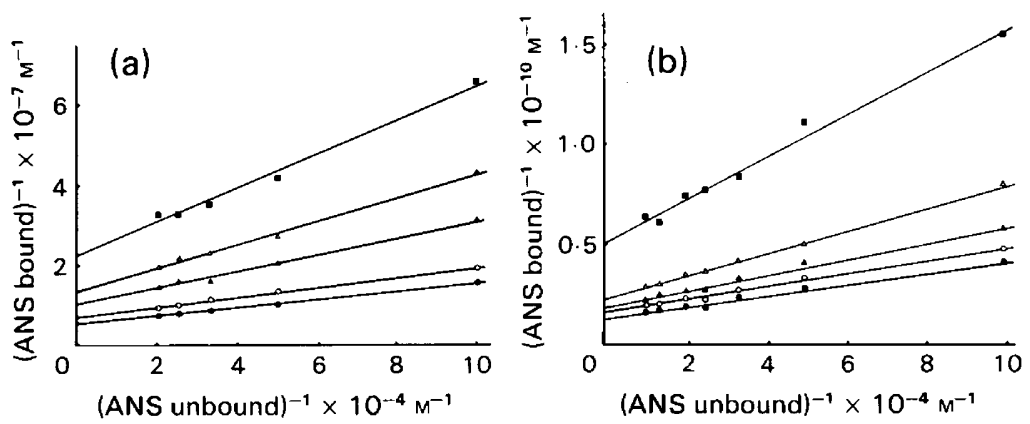

Text-fig. 5. Reciprocal of bound ANS plotted against the reciprocal of unbound ANS for (a) spermatozoa and (b) seminal plasma protein.

The effect of egg-yolk lipoprotein-sperm interaction on the quantum yield of ANS fluorescence

Samples $(1 \mathrm{ml})$ of washed spermatozoa $\left(2-10 \times 10^{8}\right.$ cells $\left./ \mathrm{ml} \mathrm{PBS}\right)$ were added to $1 \mathrm{ml}$ PBS or lipoprotein (1, 2 and $4 \mathrm{mg}$ protein $/ \mathrm{ml} \mathrm{PBS}$ ). Following equilibration at $30^{\circ} \mathrm{C}$ for $5 \mathrm{~min}, 1 \mathrm{ml}$ aliquots were centrifuged through $3 \mathrm{ml} 7.5 \%$ (w/v) Ficoll at $2000 \mathrm{~g}$ for $5 \mathrm{~min}$. After re-suspension of the cells in $2 \mathrm{ml} 500 \mathrm{nM}$-ANS in PBS and incubation at $30^{\circ} \mathrm{C}$ for $5 \mathrm{~min}$ the fluorescence was determined. Double reciprocal plots of fluorescence on number of spermatozoa 
Table 1. Interaction of ANS with washed spermatozoa and seminal plasma

\begin{tabular}{|c|c|c|c|}
\hline & $\begin{array}{c}\text { No. of } \\
\text { estimations }\end{array}$ & $\begin{array}{c}K_{\mathrm{D}} \\
\left(\times 10^{5} \mathrm{M}\right)\end{array}$ & $\begin{array}{c}n \\
\text { (pmol ANS } / 10^{6} \text { spermatozoa } \\
\text { or } / \mathrm{mg} \text { protein) }\end{array}$ \\
\hline \multicolumn{4}{|c|}{ Washed spermatozoa } \\
\hline Combined & 10 & $1.83 \pm 0.13^{*}$ & \\
\hline Klotz & 5 & $1.94 \pm 0.18$ & $98 \cdot 23 \pm 2.40$ \\
\hline Scatchard & 5 & $1.71 \pm 0.15$ & $90 \cdot 82 \pm 3.97$ \\
\hline \multicolumn{4}{|l|}{ Seminal plasma } \\
\hline Combined & 12 & $2.19 \pm 0.06^{*}$ & \\
\hline Klotz & 6 & $2.71 \pm 0.09$ & $7.30 \pm 0.23$ \\
\hline Scatchard & 6 & $2.20 \pm 0.07$ & $7.30 \pm 0.23$ \\
\hline
\end{tabular}

were extrapolated to the ordinate for each lipoprotein concentration (Text-fig. 6) and the reciprocal of the intercept was calculated as a measure of the quantum yield at infinite sperm number. The quantum yield of ANS fluorescence decreased following equilibration of egg-yolk lipoprotein with spermatozoa but the wavelength of maximum emission remained unaltered.

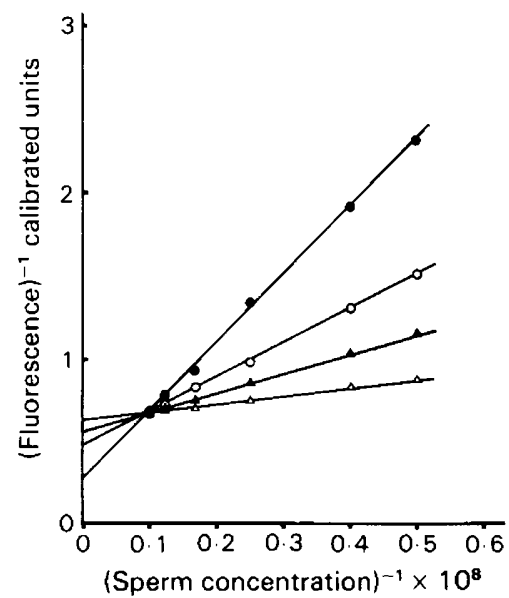

Text-fig. 6. Double reciprocal plot of ANS fluorescence against sperm concentration following incubation of spermatozoa with $0(\Theta), 1(O), 2(\Delta)$, and $4(\triangle) \mathrm{mg}$ egg-yolk lipoprotein.

The effects of egg-yolk lipoprotein- and seminal plasma-sperm interaction on ANS fluorescence

Increasing numbers of spermatozoa were added to $2 \mathrm{ml} 250 \mu \mathrm{M}$-ANS $(500 \mathrm{nmol})$ and the line 'fluorescence on number of spermatozoa' was plotted (Text-fig. 7). Similar procedures were employed to determine the fluorescence resulting from ANS interaction with egg-yolk lipoprotein (Text-fig. 7a) or seminal plasma proteins (Text-fig. $7 b$ ). Theoretical total fluorescence values $\left(F_{t}\right)$ were calculated (Text-fig. 7) for sperm-protein mixtures by summation of the values recorded separately for sperm-ANS and egg-yolk lipoprotein-ANS or seminal plasma-ANS mixtures. Increasing concentrations of spermatozoa and seminal plasma or egg-yolk lipoprotein were added to excess ANS and the fluorescence level determined $\left(\mathrm{F}_{\mathrm{a}}\right)$. The difference in fluorescence $\left(F_{a}\right.$ minus $\left.F_{t}\right)$ provided an indication of sperm-protein interaction (Text-fig. 7). Two-tailed matched pairs $t$ tests were performed to assess the null hypothesis that the addition of protein to washed spermatozoa had no effect upon fluorescence following ANS addition (i.e. $F_{a}-F_{t}=0$ ). ANS fluorescence increased after equilibration of spermatozoa with seminal plasma (mean 
increase $25.5 \pm 1.76 \% ; P<0.05)$ or egg-yolk lipoprotein $(8.9 \pm 1.76 \% ; P<0.05)$ as determined from the data illustrated in Text-fig. 7 .

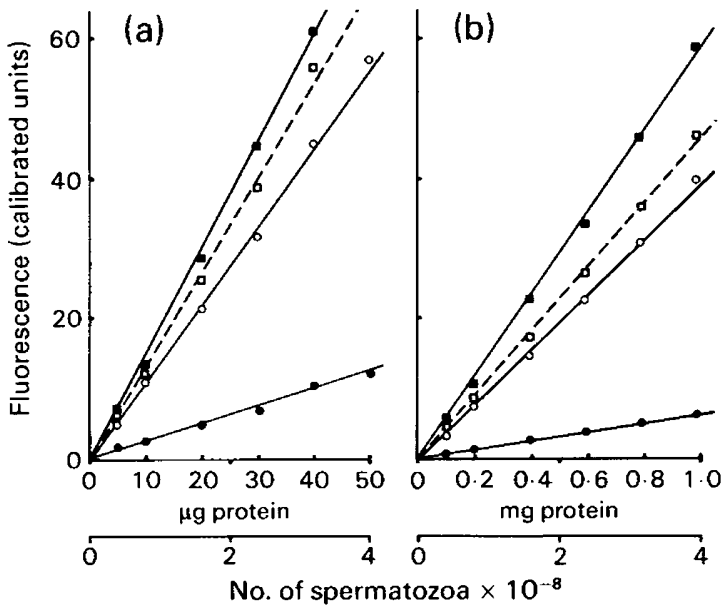

Text-fig. 7. Fluorescence resulting from the addition of increasing concentrations of (a) spermatozoa (๑), egg-yolk lipoprotein $(\mathrm{O})$ and spermatozoa + egg-yolk lipoprotein ( $(\mathbf{D})$ and (b) spermatozoa (๑), seminal plasma protein $(O)$ and spermatozoa and seminal plasma protein $(\boldsymbol{\Xi})$ to $500 \mathrm{nmol}$ ANS. Theoretical total fluorescence calculated by summation of (a) fluorescence resulting from interaction of ANS with spermatozoa and egg-yolk lipoprotein ( $\square$ ) and (b) fluorescence resulting from ANS interaction with spermatozoa and seminal plasma protein ( $\square$ ).

The effect of washing mixtures of spermatozoa and egg-yolk lipoprotein on ANS fluorescence

After washing to remove seminal plasma components, spermatozoa were re-suspended in PBS or egg-yolk lipoprotein in PBS. Aliquots $(1 \mathrm{ml})$ containing $200 \times 10^{6}$ spermatozoa or $200 \times$ $10^{6}$ spermatozoa and egg-yolk lipoprotein ( $200 \mu$ g protein) were washed 1,2 or 5 times through

Table 2. The effect of washing spermatozoa and sperm-egg-yolk lipoprotein mixtures upon subsequent ANS fluorescence: (a) $t$ test analysis to assess the effect of sperm-egg-yolk lipoprotein interaction on ANS fluorescence after washing, and (b) F ratio test analysis to investigate the progressive loss in fluorescence with washing

(a)

Fluorescence

(calibrated units)

\begin{tabular}{cccccc}
\cline { 2 - 4 } No. of washings & Spermatozoa & $\begin{array}{c}\text { Spermatozoa }+ \\
\text { egg-yolk lipoprotein }\end{array}$ & d.f. & $P$ & $\begin{array}{c}\text { Fluorescence } \\
\text { increase (\%) }\end{array}$ \\
\hline 1 & $36.87 \pm 0.35$ & $43.40 \pm 0.87$ & 4 & $<0.01$ & 17.71 \\
2 & $32.27 \pm 0.12$ & $36.87 \pm 0.95$ & 4 & $<0.01$ & 14.25 \\
5 & $16.47 \pm 0.23$ & $20.43 \pm 0.57$ & 4 & $<0.01$ & 24.04 \\
\hline
\end{tabular}

Values are mean \pm s.e.m. for three replicates.

(b)

Mean fluorescence (calibrated units)

\begin{tabular}{lccccc} 
& Washed $\times 1$ & Washed $\times 2$ & Washed $\times 5$ & d.f. & Variance \\
\hline Spermatozoa & 36.87 & 32.27 & 16.47 & 2 & $114.49^{*}$ \\
$\begin{array}{l}\text { Spermatozoa + egg-yolk } \\
\text { lipoprotein }\end{array}$ & 43.40 & 36.87 & 20.43 & 2 & $140.09^{*}$ \\
\hline
\end{tabular}

* F Ratio $=1.224$ (not significant). 
$2 \mathrm{ml} \mathrm{7.5 \%} \mathrm{(w/v)} \mathrm{Ficoll} \mathrm{in} \mathrm{PBS} \mathrm{at} 2000 \mathrm{~g}$ for $10 \mathrm{~min}$ at $30^{\circ} \mathrm{C}$. Fluorescence values were determined after re-suspension of each pellet in $2 \mathrm{ml} 2.5 \mathrm{mM}$-ANS.

Student's $t$ tests were employed to assess the null hypothesis that fluorescence resulting from interaction of ANS with washed sperm-lipoprotein mixtures was not different from that resulting from interaction of the dye with washed spermatozoa alone (Table 2a). Snedecor's F test (Variance Ratio Test) was used to confirm that the reduction in fluorescence after further washing resulted from cell loss, rather than removal of bound lipoprotein (Table $2 \mathrm{~b}$ ).

\section{Discussion}

The statistical dissociation constant $\left(K_{\mathrm{D}}\right)$ and number of dye binding sites $(n)$ were calculated to characterize ANS interaction with washed bovine spermatozoa and seminal plasma components (Table 1). The number of dye binding sites in the bovine sperm membrane $\left(6 \times 10^{7}\right.$ per cell) was considerably lower than that reported for human spermatozoa at $\mathrm{pH} 7.4\left(6 \times 10^{8}\right.$ per cell; Mercado \& Rosado, 1973). The $K_{\mathbf{D}}$ for bovine spermatozoa-ANS interaction (Table 1) was lower than that reported for human spermatozoa $\left(2.2 \times 10^{-5} \mathrm{M}\right.$; Mercado \& Rosado, 1973), suggesting that ANS has a stronger affinity for bovine than human sperm dye binding sites.

ANS may be bound by phospholipid components of the membrane bilayer (Kennedy \& Rice-Evans, 1976) or hydrophobic regions of peripheral membrane proteins (Radda \& Vanderkooi, 1972) and the fluorescence enhanced by transfer of excitation energy from neighbouring protein chromophores to the bound dye (Wallach, Ferber, Sellin, Weidekam \& Fisher, 1970). The decrease in quantum yield observed following equilibration of the lipoprotein with spermatozoa (Text-fig. 6) could suggest that membrane perturbation had occurred, increasing the polarity of the environment of the bound dye (Kennedy \& Rice-Evans, 1976), although no red shift in ANS fluorescence was seen. The increase in ANS fluorescence after equilibration of spermatozoa with egg-yolk lipoprotein, together with the reduction in quantum yield, could result from an increase in the number of dye binding sites, increased affinity of membrane binding sites for ANS or from a combination of the two mechanisms following membrane perturbation. Quantitative investigation of $K_{\mathrm{D}}$ and $n$ after lipoprotein-sperm equilibration was not possible using procedures derived from the Laws of Mass Action (Koltz et al., 1946; Scatchard, 1949) because competition between the lipoprotein and spermatozoa for the dye at limiting ANS concentrations would invalidate the necessary condition that all dye binding sites are equivalent and independent.

In contrast with the fluorescence increase reported here, equilibration of washed ram spermatozoa with egg-yolk lipoprotein has been reported to reduce membrane-localized ANS fluorescence (Watson, 1975, 1979), although the dye was used in limiting concentrations (Watson, 1975). This apparent reduction in membrane-associated ANS fluorescence might therefore have been due to competition between spermatozoa and egg-yolk components for the dye. Watson (1975) also reported that washing ram spermatozoa-egg-yolk lipoprotein mixtures before the addition of ANS restored the fluorescence. This effect could have resulted from the removal of unbound lipoprotein molecules competing for the ANS and cannot be unequivocally attributed to the stripping of bound lipoproteins from the membrane. Similarly, the preservation of ram sperm motility by egg-yolk lipoprotein in the presence of ANS (Watson, 1975) should not be attributed solely to lipoprotein-membrane interaction since competition by the lipoproteins for the dye will have contributed to reducing the proportion of ANS binding to the cells. Bovine spermatozoa equilibrated with egg-yolk lipoprotein and subsequently washed once to remove unbound molecules exhibited greater enhancement of ANS fluorescence than did spermatozoa that had not been exposed to lipoprotein (Table 2a). The degree and significance of this enhancement was not diminished by further washing of spermatozoa, although a progressive loss of ANS fluorescence resulted from the washing of spermatozoa and sperm-lipoprotein mixtures. The calculated $\mathrm{F}$ ratio (Table $2 \mathrm{~b}$ ) indicated, however, that there was no significant 
difference between the fluorescence decreases observed with spermatozoa and sperm-lipoprotein mixtures, suggesting that the reduction was due to cell loss in the washing procedures.

Although it is not possible to conclude that egg-yolk lipoprotein and ANS compete for the same sites on the bovine sperm membrane as suggested for ram spermatozoa (Watson, 1975, 1979), the results indicate that the lipoprotein interacted with membrane components leading to an increase in ANS fluorescence and a reduction in quantum yield. These results lend support to the contention that egg-yolk lipoproteins exert their cryoprotective effect by stabilizing the sperm membrane during the process of freezing and thawing.

\section{References}

Aithal, H.N., Kalra, V.K. \& Brodie A.F. (1974) Temperature-induced alterations in 8-anilino- 1 -naphthalene sulphonate fluorescences with membranes from Mycobacterium. Phlei. Biochemistry. 13, 171177.

Bialy, G., Ludwick, T.M., Hess, E.A. \& Ely, F. (1957) Influence of lipoprotein on the freezing of bovine spermatozoa. J. Dairy Sci. 40, 1189-1192.

Brocklehurst, J.R., Freedman, R.P., Hancock, D.J. \& Radda, G.K. (1970) Membrane studies with polaritydependent and excimer-forming fluorescent probes. Biochem. J. 116, 721-731.

Cox, C.P. \& Melrose, D.R. (1953) The calibration of a photo-electric adsorptiometer for the rapid estimation of counts of spermatozoa in bull semen. $J$. agric. Sci., Camb. 43, 375-379.

Datta, A. \& Penefsky, H.S. (1970) Interaction of fluorescent probes with submitochondrial particles during oxidative phosphorylation. J. biol. Chem. 245, $1537-1544$.

Foulkes, J.A. (1977) The separation of lipoproteins from egg-yolk and their effect on the motility and integrity of bovine spermatozoa. J. Reprod. Fert. 49, 277284.

Foulkes, J.A. \& Stewart, D.L. (1977) Fertility of dairy cattle after artificial insemination with semen frozen in a lipoprotein diluent. J. Reprod. Fert. 51, 175-177.

Gebauer, M.R., Pickett, B.W., Komarek, R.J. \& Gaurya, W.S. (1970) Motility of bovine spermatozoa extended in "defined" diluents. J. Dairy Sci. 53, 817-823.

Harrison, R.A.P. (1976) A highly efficient method for washing mammalian spermatozoa. J. Reprod. Fert. 48, 347-353.

Kampschmidt, R.F., Mayer, D.T. \& Herman, H.A. (1953) Lipid and lipoprotein constituents of egg-yolk in the resistance and storage of bull spermatozoa. $J$. Dairy Sci. 36, 733-742.

Kennedy, A. \& Rice-Evans, C. (1976) A spectrofluorimetric study of the interaction of glycerol mono-oleate with human erythrocyte ghosts. F.E.B.S. Letters 69, 45-50.

Klotz, I.M., Walker, F.M. \& Pivan, R.B. (1946) The binding of organic ions by proteins. J. Am. chem. Soc. 68, 1486-1490.

Lanz, R.N., Pickett, B.W. \& Komarek, R.J. (1965) Effect of lipid additives on pre- and post-freeze survival of bovine spermatozoa. J. Dairy Sci. 48, 1692-1697.

Laurence, D.J.R. (1952) A study of the adsorption of dyes on B.S.A. by the method of polarization of fluorescence. Biochem. J. 51, 168-180.
Lowry, O.H., Rosebrough, N.J., Farr, A.L. \& Randall, K.J. (1951) Protein measurements with the Folin phenol reagent. J. biol. Chem. 193, 265-275.

Martin, I.C.A. (1963) Effects of lecithin, egg-yolk, fructose and period of storage at $5^{\circ} \mathrm{C}$ on bull spermatozoa deep-frozen to $-79^{\circ} \mathrm{C}$. J. Reprod. Fert. 6, 441-449.

Masuda, H. \& Nishikawa, Y. (1972) Studies on the substances in egg-yolk affecting the viability and metabolism of spermatozoa. III. Substances in the non-dialyzable portion of egg-yolk promoting the survival of spermatozoa of goats, bulls and horses. Jap. J. Zootech. Sci. 44, 355-359.

Mercado, E. \& Rosado, A. (1973) Structural properties of the membrane of intact human spermatozoa. A study with fluorescent probes. Biochim. Biophys. Acta 298, 639-652.

Peterson, R.N., Bundman, D. \& Freund, M. (1978) Use of a fluorescent dye to measure drug induced changes in the membrane potential of boar spermatozoa. Life Sci. 22, 659-666.

Radda, G.K. \& Vanderkooi, J. (1972) Can fluorescent probes tell us anything about membranes? Biochim. Biophys. Acta 265, 509-459.

Scatchard, G. (1949) The attractions of proteins for small molecules and ions. Ann. N.Y. Acad. Sci. 51, 660-672.

Wallach, D.F.H., Ferber, E., Sellin, D., Weidekam, E. \& Fisher, H. (1970) The study of lipid-protein interactions in membranes by fluorescent probes. Biochim. Biophys. Acta 203, 67-76.

Watson, P.F. (1975) The interaction of egg-yolk and ram spermatozoa studied with a fluorescent probe. $J$. Reprod. Fert. 42, 105-111.

Watson, P.F. (1979) An objective method for measuring fluorescence of individual sperm cells labelled with 1-anilino naphthalene-8-sulphonate (ANS) by means of photomicrography and densitometry. J. Microsc. $117,425-429$.

Weber, G. \& Laurence, D.J.R. (1954) Fluorescent indicators of adsorption in aqueous solution and on the solid phase. Biochem. J. 56, 31-Proc.

Weber, G. \& Young, L.B. (1964a) Fragmentation of bovine serum albumin by pepsin. I. The origin of the acid expansion of the albumin molecule. J. biol. Chem. 239, 1415-1423.

Weber, G. \& Young, L.B. (1964b) Fragmentation of bovine serum albumin by pepsin. II. Isolation, amino acid composition and physical properties of the fragments. J. biol. Chem. 239, 1424-1431. 